\section{Summary points}

Death rates from ruptured aortic aneurysm are around $50 \%$

Aortic aneurysms can be detected with a simple ultrasound examination

Screening has been shown to reduce deaths by $42 \%$

A population screening programme in the United Kingdom could save several thousand lives at reasonable cost

\section{Conclusion}

The scientific arguments for a national screening programme for aneurysms are cogent. We believe that the United Kingdom's family doctor based health system puts it in an ideal position to be the first country to start national screening. The final decision is now political. It is a shame that aneurysm disease lacks a cohesive pressure group to encourage the process.

Contributors and sources: BPH designed and started the Gloucestershire aneurysm screening programme. JJE, MRW, and KRP have supported the programme and helped to run it. ES and BPH manage the GASP database and provided all the data and the figure.

Funding: The Gloucestershire screening programme is funded by the NHS Trust. The aneurysm screening co-ordinator is an employee of Gloucestershire Hospitals NHS Trust. The four consultants receive no additional remuneration for the screening project.

Competing interests: None declared.

Office of Population Census and Surveys. Mortality statistics:cause, England and Wales 1993. London: HMSO, 1995.

2 Best VA, Price JF, Fowkes FGR, Persistent increase in the incidence of abdominal aortic aneurysm in Scotland 1981-2000. Br J Surg 2003:90:1510-5.

3 Heather BP, Poskitt KR, Earnshaw JJ, Whyman M, Shaw E. Population screening reduces mortality rate from aortic aneurysm in men. BrJ Surg 2000;87:750-3

4 Wilson JMG, Junger G. Principles and practice of screening for diseases. Geneva: World Health Authority, 1968. (Public health paper No 34.)

5 UK National Screening Committee. Criteria for appraising the viability, effectiveness, and appropriateness of a screening programme http. www.nsc.nhs.uk/pdfs/criteria.pdf (accessed 23 Mar 2004).
6 Scott RAP, Bridgewater SG, Ashton HA. Randomised clinical trial of screening for abdominal aortic aneurysm in women. $\mathrm{Br} J$ Sur 2002;89:283-5.

7 Multicentre Aneurysm Screening Study Group. The multicentre aneurysm screening study (MASS) into the effect of abdominal aortic aneurysm screening on mortality in men: a randomised controlled trial. Lancet 2002;360:1531-9.

8 Multicentre Aneurysm Screening Study Group. Multicentre Aneurysm Screening Study (MASS): cost effectiveness analysis of screening for abdominal aortic aneurysms based on four year results from a abdominal aortic aneurysms based on four year
randomised controlled trial. BMJ 2002;325:1135-8.

9 Vardulaki KA, Walker NM, Couto E, Day NE, Thompson SG, Ashton HA, et al. Late results concerning feasibility and compliance from a randomised trial of ultrasonographic screening for abdominal aortic aneurysm. Br J Surg 2002;89:861-4.

10 Lindholt JS, Juul S, Fasting H, Henneberg EW. Hospital cost and benefits of screening for abdominal aortic aneurysms. Eur I Vasc Endovasc Sur 2002:23:55-60.

11 Jamrozik K, Norman PE, Spencer CA, Parsons RW, Tuohy R, Lawrence-Brown MM, et al. Screening for abdominal aortic aneurysm: lessons learned from a population based study. Med J Aust 2000;173:34550.

12 Beard JD. Screening for abdominal aortic aneurysm. Br J Surg 2003;90:515-6.

13 Greenhalgh RM, Powell JT. Screening men for aortic aneurysm. BMJ 2002;325:1123-4.

14 Muir Gray JA. Screening for abdominal aortic aneurysm [letter]. BrJ Surg 2003;90:1165

15 Crow P, Shaw E, Earnshaw JJ, Poskitt KR, Whyman MR, Heather BP. A single normal ultrasonographic scan at age 65 years rules out significant aneurysm disease for life in men. Br J Surg 2001;88:941-4

16 Irvine CD, Shaw E, Poskitt KR, Whyman MR, Farnshaw JJ Heather BP. A comparison of the mortality rate after elective repair of aortic aneurysms detected either by screening or incidentally. Eur J Vasc Endovasc Surg 2000;20:374-8.

17 McCarthy RJ, Shaw E, Whyman MR, Earnshaw JJ, Poskitt KR, Heather BP Recommendations for screening intervals for small aortic aneurysms. $B$ J Surg 2003;90:821-6.

18 United Kingdom Small Aneurysm Trial Participants. Long term outcomes of immediate repair compared with surveillance of small abdominal aortic aneurysms. N Engl J Med 2002;346:1445-52.

19 Michaels JA. Use of mortality rate after aortic surgery as a performance indicator. BrJ Surg 2003;90:827-31.

20 Vascular Surgical Society of Great Britain and Ireland. National Vascular Database report 2002./www.vssgbi.org/Docs/NVD2002.pdf (accessed 23 Mar 2004).

21 Prytherch DR, Ridler BMF, Beard JD, Earnshaw JJ, Audit and Research Committee of Vascular Surgical Society of Great Britain and Ireland. A model for national outcome audit in vascular surgery. Eur J Vasc Endovas Surg 2001;21:477-83.

22 Thompson MM. Controlling the expansion of abdominal aortic aneurysms. Br J Surg 2003;90:897-8.

23 Bown MJ, Sutton AJ, Bell PRF, Sayers RD. A meta-analysis of 50 years of ruptured abdominal aortic aneurysm repairs. Br J Surg 2002;89:345-50.

24 Veith FJ, Ohki T, Lipsitz EC, Suggs WD, Cynamon T. Treatment of ruptured abdominal aneurysms with stent grafts: a new gold standard? Semin Vasc Surg 2003;16:171-5.

25 Hinchcliffe RJ, Braithwaite BD, Hopkinson BR. The endovascular management of ruptured abdominal aortic aneurysms. Eur J Vasc Endovasc Surg 2003;25:191-201.

(Accepted 11 March 2004)

\title{
Lessons from developing nations on improving health care
}

\author{
Donald M Berwick
}

Evaluation of projects to improve health care in resource poor countries can provide ideas and inspiration to the often stalled efforts in healthcare organisations of wealthy nations

Institute for

Healthcare

Improvement,

375 Longwood

Avenue, Boston,

MA 02215, USA

Donald M Berwick

president

dberwick@ihi.org

BMJ 2004;328:1124-9
Improvement is, I believe, an inborn human endeavour. My belief arises mostly from watching children. You cannot find a healthy child who does not try to jump higher or run faster. It takes no outside incentive. Children smile when they succeed; they smile to themselves. And so, it is my premise that almost all human organisations contain in their workforce an internal demand to improve their work. It saddens me how few organisations seem to know that, and fewer still act on it. Improvement is not forcing something; it is releasing something.
Nevertheless, improving organisations is not easy. The barriers are many, and those barriers can produce a sense of helplessness and futility. Failing to improve, we feel unfortunate and wish that someone, somewhere, would give us that extra missing resource that we imagine would make change possible. "We want to make care better," goes the complaint, "but they won't let us."

It might help us in the wealthy world to pause for a moment and reflect not on what we lack but on our good fortune. And the best way to do that is to look at those with less in their hands. In the past few years, I 


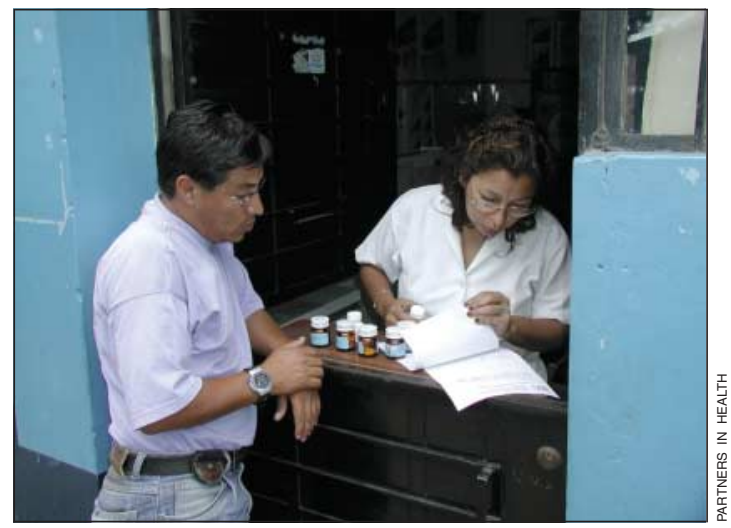

Patient receives tuberculosis treatment as part of Carabayllo project

have been fortunate to do some work in resource poor countries, which have $90 \%$ of the people but only $10 \%$ of the world's wealth. My work in these settings has convinced me not only that it is possible to improve health care in resource poor settings but also that improvement may even be more feasible than it is in wealthy ones. Two remarkable projects in progress in the developing world show the tremendous resourcefulness, innovation, and potential for improvement in that resource constrained context, with potentially important lessons for caregivers in richer places. ${ }^{1}$

\section{Carabayllo project}

Harvard doctors Paul Farmer and Jim Yong Kim have been working for almost a decade in Carabayllo-a poor neighbourhood of 100000 people in Lima, Peru. Their work, undertaken through Partners in Health, based in Boston, and Socios en Salud, its sister organisation in Lima, has shown that multidrug resistant tuberculosis, previously thought to be untreatable in resource poor settings, can in fact be cured in $80 \%$ or more of cases. This success has come from a well developed approach involving, among other things, community health workers, careful expert based treatment planning, anticipatory management of complications, aggressive management of drug supplies, maintenance of local registries, and other local innovations. ${ }^{2}$ Gaining confidence from the Carabayllo prototype, the World Health Organization and officials in Peru, as well as some important funders, have become intrigued by the idea that first world standards of care can be successfully used in resource poor settings. ${ }^{3}$

Partners in Health, Socios en Salud, the Peruvian Ministry of Health, and the Institute for Healthcare Improvement have combined forces to organise a programme aimed at improving tuberculosis care to world class levels, building on and adapting the Carabayllo model. The programme uses multidisciplinary teams in 41 community based clinics, in five districts in Lima. These districts together account for almost $30 \%$ of the cases of tuberculosis in Peru.

The 41 teams have been working for more than two years, and their results compare favourably with those achieved in similar collaborative improvement projects in the United States, Canada, United Kingdom, Sweden, and Norway. Many of the teams have mastered the model for improvement devised by Langley and colleagues, ${ }^{4}$ and understand measurement, reporting, and local tests of change as well as any teams I have seen in far richer settings. Their goals are ambitious, and they are working with a strong conceptual model founded in modern principles of chronic care management. ${ }^{56}$

The Peru project is still at an early stage, in which successes are measured mostly through process changes and the emergence of bold new aims. We will see in the coming years if the burden of tuberculosis falls as a consequence.

\section{Russian examples}

Perhaps the best healthcare improvement projects in resource poor settings, arguably some of the best anywhere, are now under way in Russia under the expert guidance of Rashad Massoud, one of the foremost experts in large scale improvement. Dr Massoud and his Russian colleagues started projects in two of the 89 Russian states focusing on specific, high burden conditions. In Tver, the targets included respiratory distress syndrome in infants and pregnancy induced hypertension in women. In Tula, efforts focused on adult hypertension. All these conditions are often fatal in Russia. ${ }^{7}$

The projects include improvement teams and redesign efforts, again using the model for improvement, ${ }^{48}$ in collaborative structures linking several sites-clinics or hospitals-in a common system of measurement, testing, and learning together. Tula began with 20 clinics, expanding within 18 months to over 500 . Tver began with five hospitals and their associated maternity clinics, expanding to all 42 hospitals in the state and every maternity clinic. The box gives a few of the results.

The achievements in Russia illustrate well a premise that many quality improvement experts have tried to teach the Western world for decades-namely, that higher quality (often far higher quality) can cost less (often far less) than defective quality. ${ }^{910}$ It is surprising that such efficiencies can be found in settings as resource starved as Tver and Tula, and

\section{Results of Russian health improvement schemes}

\section{Tula (adult hypertension)}

Sevenfold increase in patients managed for hypertension at primary care level

$70 \%$ success rate in controlling blood pressures $85 \%$ reduction in admissions for hypertension $60 \%$ reduction in admissions for hypertensive crises $41 \%$ reduction in hospital costs and 39\% increase in primary care costs with a net saving for overall hypertension care costs of $23 \%$

Tver (maternal hypertension and neonatal respiratory distress syndrome)

$64 \%$ fewer deaths from respiratory distress syndrome in newborns

$99 \%$ reduction in hypothermia in newborns

Neonatal mortality halved

Maternal deaths almost eliminated

Pregnancy induced hypertension:

Incidence reduced from $44 \%$ to $6 \%$

$60 \%$ reduction in hospital admissions

$87 \%$ decrease in associated costs of care 


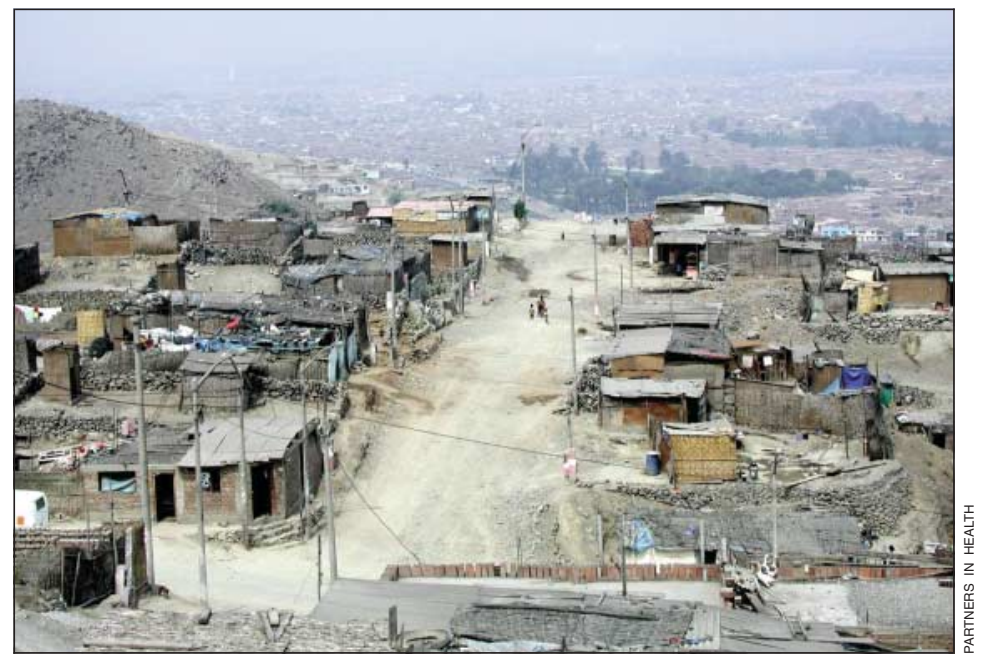

Carabayllo district of Lima: work here shows tuberculosis can be treated in resource poor settings tiating these goals with other stakeholders. A typical planning group meeting in Peru before the project charter was written included 20 to 30 people, three or four times as many as would attend an equivalent planning meeting in the United States. But this openness and struggle produced a breadth of agreement on what would be attempted that, in retrospect, could probably have been achieved no other way.

Thirdly, the bold goals seem to fit well with what might be called a results oriented workforce. In these resource poor settings, the doctors, nurses, health aides, and others seem riveted on the community need, which then gets reflected in the fourth and fifth elements: a sort of foot-tapping bias toward action (trying something now rather than later), and a deeply pragmatic mindset that finds theory somewhat boring but practical instruction helpful.

In short, in the arena of aims, the people in Russia and Peru are bold and pragmatic at the same time. They want to try something hard and real. Retreats to discuss culture change would leave them cold; they haven't the time. Give them the manual and get out of the way.

\section{Team based improvement}

The second major asset in these projects is a bias toward "teamness." In these settings, the sometimes highly honoured position of doctors can be a problem, impeding frank exchange and job redesign. But it seems more than counterweighted by the deeply held understanding that teams matter. Even in the cities, you feel that a sense of community is familiar and dominant. When I first arrived in Carabayllo, I was invited to join in a funeral procession for the father of one of the key nurses in Socios en Salud. Not only were all of the Socios staff there, but so, it seemed, was half the population of Carabayllo. Team is much more than an abstract construct to these people; it is a reflection of the living social context

On the other hand, even though they easily comprehend the essential role of teams, people in developing countries seem less familiar with formal, self conscious views of health care as a system. Modern approaches to improvement try to make systems visible, so that they can be understood and worked on. But the first time the Carabayllo group in Lima considered their own work process in a flow chart, the exercise launched a nearly revolutionary set of insights. They had never seen their interdependencies clearly. When asked, "What does the doctor supply to the nurse?" they responded with a stunned, embarrassed silence. The question had apparently never before occurred to them. A pause followed, then raucous laughter and noise as the room exploded in ideas and jests, begun, as it would have to be, by a doctor who loosened up and shared his thoughts out loud.

Teams in these settings learn and use the specific methods of process improvement well-they follow the instructions. For example, most good improvement models encourage local teams to measure their progress frequently and plot these measurements graphically. Such graphs allow the teams to keep tabs on their progress and help them learn from their own, local experiments. Few American teams actually follow that method assiduously. They often fail to measure their progress at all, or they measure too infrequently 
to support rapid learning. This resistance to measurement seems less common in resource poor settings. If the model says measure, the teams measure. Maybe this has to do with culture, politics, and bureaucracy in these settings, but, whatever the cause, it makes learning easier.

\section{Building infrastructure}

Leaders in resource poor settings often excel in creating local infrastructures to support improvement efforts. That is a bit of a paradox, since it is often the support systems that have suffered the most; they don't have much infrastructure to begin with. It may be those very constraints that have nurtured a kind of cleverness to do more with less-"duct tape" thinking.

In one instance, a team from a maternal and child health clinic in the Chitral province in Northern Pakistan was developing some interesting projects on early intervention in pregnancy. Western experts asked them to think about ways they could track the effects of their work. In the United States, of course, that might have led to a grant application, a consultancy contract, $\$ 500000$ of capital, and a new computer system. The team from Chitral found a simpler answer. "That's easy," said the doctor who was leading the team. "We will count small graves." When a team or an organisation really cares to improve, measurement is a challenge, but it is rarely the rate limiting bottleneck.

Some call this inventiveness bootstrappingpulling yourself up by your boot straps. Resourceful teams are willing to find clever ways to use what they already have. What they already have includes the community in which their efforts are embedded, a resource that many American healthcare organisations seem to discount or not even notice.

\section{Altering the policy environment}

Local and pragmatic improvement efforts in developing nations seem especially agile at handling the wider policy environment. This fourth asset is, of course, more necessary in developing nations than the United States because ministries of health tend to have a core role. Ministries, as in Peru and Russia, tend to be the conveners, funders, employers, and rule makers for the relevant care system, even though strong private care systems often exist in parallel. The leaders of improvement at the local and district levels, such as clinic directors, front line doctors and nurses, and junior ministry officials, seem to know how to keep the projects going despite shifting political winds and changing administrative faces. They "manage up" well (they have always had to do so just to get through the day) and they bring that balance, gracefulness, wisdom, and long sightedness into the improvement effort to help stabilise it. (The Peru project has remained active through four changes in minister of health.)

\section{Scaling up improvement}

Some of the best work in the world on spreading changes, scaling up improvement, may be in the developing world. Dr Massoud's successes in Tver and Tula have now been noticed by the central Russian Federation Health Ministry, and the projects are being replicated in 39 states, covering almost half the population of Russia. That is scaling up from tens to hundreds, to thousands, to millions, to tens of millions within little more than three years ( $\mathrm{R}$ Massoud, personal communication). No one has ever accomplished this for complex health system improvements. Peru is further behind, but given ministry constancy, first world tuberculosis care could be scaled up from a population of 100000 to all of Peru, a population of 28.5 million, again within three years.

A step forward, now starting in Russia, is to use internet communication to decrease the need to travel to places that are difficult to access. Web based work areas, allowing teams from many different locations to share data and engage in conversations, now support the spread processes in Russia, and global efforts to use existing information and communications infrastructure to facilitate improvement are under way. ${ }^{112}$

\section{Barriers to progress}

That is the good news. But, of course there are serious barriers in these settings, as well. A few examples follow:

\section{Politics}

Politics really does matter, and the effects of political change cannot always be mitigated. The Peru project is currently trying to reconstruct itself after the sudden and unexpected resignations of several key officials within the ministry of health, all of whom had strongly encouraged the project. Their loss has worried the teams.

\section{Infrastructure}

Although clever bootstrapping has managed to provide some infrastructures, others are lacking. In Peru, the project temporarily stalled because of cross cutting problems such as a slow chain of pharmaceutical supply. Teams began running out of drugs because of importation obstacles. At times they lacked sputum containers that were in warehouses but somehow did not get out to the clinics. The leaders of the Peru project came up with the idea of team 42, a ministry level support team using the same improvement processes as the 41 local teams but using them on central support systems that the local teams depend on.

\section{Red tape}

Despite the courage we see in these settings, projects sometimes suffer, as many Western organisations do, from a lack of willingness among senior leaders to give the local teams the licence they need to try new methods. For example, success of the Peru project depends on revised treatment algorithms for patients in whom first line antibiotic treatment fails. Everyone knows that, but the project still does not have a green light from the ministry of health for the 41 local teams to switch to a well developed alternative protocol that differs from the current national scheme. Until they do so, they cannot show the superiority of the new algorithm.

\section{Self sufficiency}

As helpful as the skills of external advisers are, it is crucial for spread and sustainability that dependency on outside consultation falls steadily. This is going well in Russia, where the skills to manage collaborative improvement are now growing fast in many states, but in other settings, local leaders still find it easier to bring in outsiders than to develop strategic human resource capabilities from within. 


\section{Travel}

Although collaborative projects are as valuable in the developing world as in the developed world, getting people together physically is much more difficult. The Institute for Healthcare Improvement took part in planning a programme to scale up HIV/AIDS care in Mozambique. The programme involved 24 population centres in a nation almost twice the size of California. Although teams and leaders came together in March to kick off the project in the nation's capital, Maputo, the cost of travel, irregular flight schedules, and human resource constraints at each site posed challenges to the important gathering. While an equivalent project in the United States would hold follow up meetings within months, making such arrangements in that time frame may prove too complicated and expensive in Mozambique, and the country may have to find other ways to help sites work together over time.

\section{Leadership}

Especially in the sub-Saharan countries, the opportunity costs for leaders who devote their time to improvement are large because the pool of skilled, mature system level leaders is extremely small. The same people who can lead a national effort on tuberculosis care or HIV/AIDS will be the best candidates for other high level governmental functions. A leadership development strategy is an inescapable part of any hopeful plan for improvement of care in developing nations.

\section{Language}

Developing countries face language barriers that most developed nations do not. It is crucial that the improvement work be embedded in local teams, clinics, districts, and towns. But the plurality of languages in most of these settings may confound useful exchanges and mutual assistance and also make it hard to use outside advice efficiently.

\section{Roles}

Just as in Western countries, developing countries may have fossilised and dysfunctional rules and habits about job roles, even when key roles are largely vacant. In one sub-Saharan country with a high AIDS burden, the general belief remains that only physicians ought to administer injectable drugs; but the country has too few physicians to deliver that care. Even if drugs arrive, they cannot be used successfully until the rule changes.

\section{Scalability}

There is a technical barrier to scale up of changes when the prototypes have been built without attention to their inherent scalability. The resource realities of these impoverished settings are not going to change quickly, and therefore, scalable models, built from the start with an eye to their replication and spread under the current or near term circumstances, are far more valuable than models built under more ideal assumptions, in central cities that do not reflect the contexts of the rest.

\section{Lessons for developing countries}

Notwithstanding the barriers, nothing in my two decades of work on healthcare improvement has inspired and amazed me quite so much as these early days of systemic improvement in the developing world.

\section{Summary points}

Many barriers exist to hinder improvement in health care in both developing and developed countries

Projects in Peru and Russia show how large healthcare improvements can be managed successfully with limited resources

Developed countries can learn from the approaches used in these countries

The key lessons are to keep targets and measurement processes simple and to make full use of teams

Time after time, in setting after setting, I find exactly the combination of intensity, cleverness, hard work, and optimism that we all need for this tough job of change to go well. Here are a few of the lessons I am starting to learn from the people whose form of wealth is so different from mine.

Simplify everything-The core of improvement need not be complex. Set aims, track results, find great ideas, and change something every day to find the better ways. Involve everyone you can, and do not assume that the rules of today must be the rules of tomorrow. I find elegance in the simplicity of approach that people who have little to waste have a knack for. Complexity is waste

Take teams seriously-Improvement is about cooperation, and no one should trump the team. Uncooperativeness is waste.

Be pragmatic about measurement-Information technology is nice but not the point at all. Use the least measuring that helps, not the most that you can think of. Too much counting is waste.

Strip the support system for improvement to a minimum-Flatten the organisation. Consultants should make it their job to become unnecessary as fast as they can. Dependency is a form of waste.

Manage the political interface wisely-It is wiser to use it than to change it. Naivety is waste.

Help patients become advocates for change-Their stake is the highest, and their voices count the most. Keeping patients silent is waste.

Go quickly. Start now-Delay is waste.

Make spread a system - Find the latent structures, the channels along which change can flow, and use them from the start. Go, as Tver, from 5 to 50 to all, then to the neighbours, and then to their neighbours. Isolation is waste.

And finally, don't complain - I have visited settings in Rwanda, Mozambique, Peru, and Palestine where every person I met had 100 times more reasons to complain than I do. And none did. Complaint is waste.

I believe now that the duty to help the world's poor nations is everyone's. I wish my own nation were in the lead, and someday maybe it will be. Meanwhile, we can deepen our commitments. My limited but consistent experience shows that we will meet in the developing world a level of will, skill, and constancy that may put 
ours to shame. We may well find ourselves not the teachers we thought we were, but students of those who simply will not be stopped under circumstances that would have stopped us long ago.

Contributors and sources: DB is chief executive officer of the Institute for Healthcare Improvement and a leading authority on healthcare improvement in the United States. He is working with colleagues from the institute, the University Research Consortium in Bethesda, and the MacColl Institute for Healthcare Innovation in Seattle to better understand the proper application of healthcare improvement approaches in developing settings.

Competing interests: None declared.

1 Smits HL, Leatherman S, Berwick DM. Quality improvement in the developing world. Int J Ouality Health Care 2002;14:439-40.

2 Farmer P, Kim JY. Community based approaches to the control of multiFarmer P, Kim JY. Community based approaches to the control of multi-
drug resistant tuberculosis: introducing "DOTS-plus." BMJ drug
1998:317:671-4

3 Gupta R, Kim JY, Espinal MA, Caudron JM, Pecoul B, Farmer PE, et al. Responding to market failures in tuberculosis control. Science 2001;293:1049-51.
4 Langley GL, Nolan KM, Nolan TW, Norman CL, Provost LP. The improvement guide: a practical approach to enhancing organizational performance. San ment guide: a practical approach

Francisco:Jossey-Bass, 1996.
Wagner EH. Chronic disease management: What will it take to improve care for chronic illness? Effective Clin Pract 1998;1:2-4.

6 Pruitt S, Annandale S, Epping-Jordan J, Fernandez Diaz J, Khan M, Kisa A, et al. Innovative care for chronic conditions: building blocks for action. Geneva: World Health Organization, 2002

7 Abdallah H, Chernobrovkina O, Karatkova A, Massoud R, Scheglova M. Evidence-based guidelines improve health outcomes and reduce cost of care for women with pregnancy-induced hypertension in Tver, Russia. Bethesda: Quality Assurance Project (in press).

8 Berwick D, Nolan T. Physicians as leaders in improving health care. Ann Intern Med 1998;128:289-92.

9 Deming WE. Out of the crisis. Cambridge, MA: MIT Press, 2000.

10 Deming WE. The new economics for industry, government, education. Cambridge, MA: Massachusetts Institute of Technology Center for Advanced Engineering Study, 1994.

11 Edeier TT. Disseminating health information in developing countries: the role of the internet. $B M J .2000 ; 321: 797-800$.

12 Rotich JK, Hannan TJ, Smith FE, Bii J, Odero WW, Vu N, et al. Installing and implementing a computer-based patient record system in sub-Saharan Africa: the Mosoriot medical record system.J Am Med Inform Assoc 2003;10:295-303.

(Accepted 17 April 2004)

\title{
Linking disease control programmes in rural Africa: a pro-poor strategy to reach Abuja targets and millennium development goals
}

\author{
David H Molyneux, Vinand M Nantulya
}

The effectiveness of programmes to tackle malaria could be improved by linking them to initiatives to prevent other diseases

The global community has committed itself to halving the morbidity and mortality from malaria worldwide by 2010 through the Roll Back Malaria initiative (box). ${ }^{1}$ This goal was endorsed by the African heads of state at a summit held in Abuja, Nigeria, in April 2000. ${ }^{2}$ The leaders set three targets to achieve by 2005 : $60 \%$ of malaria patients to have prompt (within 24 hours of malaria attack), affordable, and appropriate treatment; $60 \%$ of all pregnant women to have access to preventive presumptive intermittent therapy; and $60 \%$ of children under 5 years and pregnant women to be sleeping under insecticide treated mosquito nets. However, progress is currently slow. We suggest how progress could be increased through linking disease control or elimination programmes under way in Africa to malaria control programmes. These programmes, many of which are based on drug donations, bring additional public health benefits to affected populations such as reduced anaemia, improved nutrition, better child growth and development, and higher school attendance. Such a strategy would have a rapid effect on malaria morbidity and mortality among underserved populations.

\section{Feasibility of targets}

The tools for achieving the Abuja targets already exist-namely, insecticides, bed nets, and highly effective drugs. However, they are not being provided fast enough to the people who need them. Most malaria attacks are managed outside the formal health service as an out of pocket expenditure in the poorest countries. $^{3-5}$ Indeed, because of the AIDS epidemic, children with malaria may be orphans cared for by their grandmothers. Thus, for many countries in sub-Saharan Africa, assuring treatment within 24 hours after a malaria attack means that antimalarial drugs have to be available at an affordable price and in simple formulations from the lowest level of the healthcare system - that is, informal care givers in rural villages. It will not be easy for poor countries to reach this target of prompt treatment, especially if the more

Further examples of programmes that could be linked with - malaria control are on bmj.com

Editorial by Yamey

Lymphatic Filariasis Support Centre, Liverpool School of Tropical Medicine, Liverpool L3 5QA David H Molyneux director

Global Fund to Fight AIDS, Tuberculosis and Malaria, Geneva 1216, Switzerland Vinand M Nantulya senior adviser

Correspondence to: D H Molyneux fahy@liv.ac.uk

BMJ 2004;328:1129-32

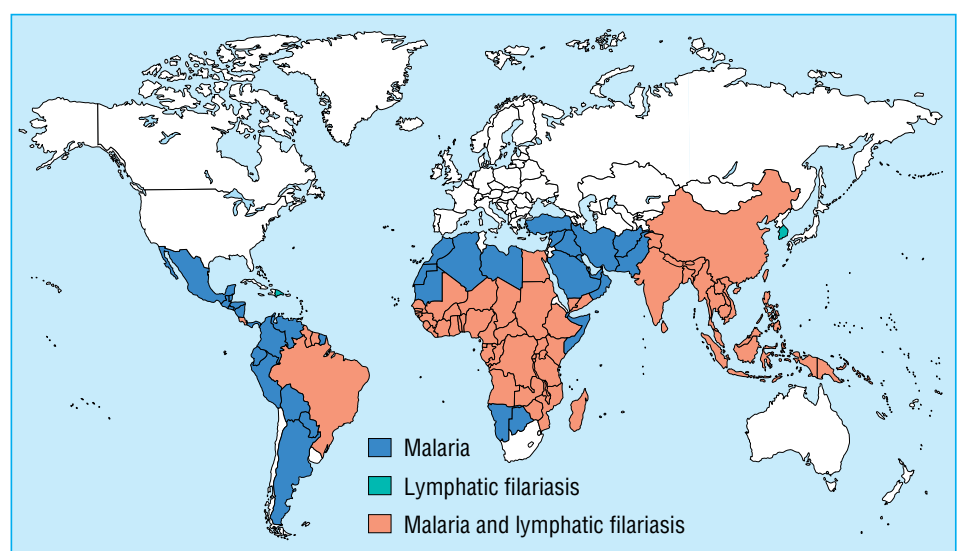

Map showing countries with endemic malaria and lymphatic filariasis in 2003 